\title{
Strain Differences in Stress Responsivity Are Associated with Divergent Amygdala Gene Expression and Glutamate-Mediated Neuronal Excitability
}

\author{
Khyobeni Mozhui, ${ }^{1 *}$ Rose-Marie Karlsson, ${ }^{2 *}$ Thomas L. Kash, ${ }^{3}$ Jessica Ihne, ${ }^{2}$ Maxine Norcross, ${ }^{2}$ Sachin Patel, ${ }^{4}$ \\ Mollee R. Farrell, ${ }^{5}$ Elizabeth E. Hill, ${ }^{5}$ Carolyn Graybeal, ${ }^{2}$ Kathryn P. Martin, ${ }^{2}$ Marguerite Camp, ${ }^{2}$ Paul J. Fitzgerald, ${ }^{2}$ \\ Daniel C. Ciobanu, ${ }^{6}$ Rolf Sprengel, ${ }^{7}$ Masayoshi Mishina, ${ }^{8}$ Cara L. Wellman, ${ }^{5}$ Danny G. Winder, ${ }^{3}$ Robert W. Williams, ${ }^{1}$ \\ and Andrew Holmes ${ }^{2}$ \\ ${ }^{1}$ Department of Anatomy and Neurobiology, University of Tennessee Health Science Center, Memphis, Tennessee 38163, ${ }^{2}$ Section on Behavioral Science \\ and Genetics, Laboratory for Integrative Neuroscience, National Institute on Alcohol Abuse and Alcoholism, National Institutes of Health, Rockville, \\ Maryland 20852, ${ }^{3}$ Department of Molecular Physiology and Biophysics, Vanderbilt University School of Medicine, Nashville, Tennessee 37232, \\ ${ }^{4}$ Department of Psychiatry, Vanderbilt University School of Medicine, Nashville, Tennessee 37232, ${ }^{5}$ Department of Psychological and Brain Sciences, \\ Indiana University, Bloomington, Indiana 47405, ${ }^{6}$ Department of Animal Science, University of Nebraska, Lincoln, Nebraska 68583, ${ }^{7}$ Max-Planck Institute \\ for Medical Research, D-69120 Heidelberg, Germany, and ${ }^{8}$ Department of Molecular Neurobiology and Pharmacology, Graduate School of Medicine, \\ University of Tokyo, Tokyo, 113-0033 Japan
}

Stress is a major risk factor for numerous neuropsychiatric diseases. However, susceptibility to stress and the qualitative nature of stress effects on behavior differ markedly among individuals. This is partly because of the moderating influence of genetic factors. Inbred mouse strains provide a relatively stable and restricted range of genetic and environmental variability that is valuable for disentangling gene-stress interactions. Here, we screened a panel of inbred strains for anxiety- and depression-related phenotypes at baseline (trait) and after exposure to repeated restraint. Two strains, DBA/2J and C57BL/6J, differed in trait and restraint-induced anxiety-related behavior (dark/light exploration, elevated plus maze). Gene expression analysis of amygdala, medial prefrontal cortex, and hippocampus revealed divergent expression in DBA/2J and C57BL/6 J both at baseline and after repeated restraint. Restraint produced strain-dependent expression alterations in various genes including glutamate receptors (e.g., Grinl, Grikl). To elucidate neuronal correlates of these strain differences, we performed ex vivo analysis of glutamate excitatory neurotransmission in amygdala principal neurons. Repeated restraint augmented amygdala excitatory postsynaptic signaling and altered metaplasticity (temporal summation of NMDA receptor currents) in DBA/2J but not C57BL/6J. Furthermore, we found that the C57BL/6J-like changes in anxiety-related behavior after restraint were absent in null mutants lacking the modulatory NMDA receptor subunit Grin2a, but not the AMPA receptor subunit Grial. Grin2a null mutants exhibited significant $(\sim 30 \%)$ loss of dendritic spines on amygdala principal neurons under nonrestraint conditions. Collectively, our data support a model in which genetic variation in glutamatergic neuroplasticity in corticolimbic circuitry underlies phenotypic variation in responsivity to stress.

\section{Introduction}

Although stress is a known risk factor for various neuropsychiatric disorders, ranging from mood and anxiety disorders to schizophrenia and attention deficit hyperactivity disorder, individuals differ greatly in their susceptibility to stress. Moreover, the manner in which stress manifests phenotypically varies con-

\footnotetext{
Received 0ct. 7, 2009; revised Feb. 7, 2010; accepted Feb. 18, 2010.

This work was supported by the National Institute on Alcohol Abuse and Alcoholism (NIAAA; Z01-AA000411) and National Institute of Mental Health (NIMH; Z01-MH002784) Intramural Research Programs, and by National Institute on Drug Abuse, NIMH, and NIAAA HPG Grant P20-DA 21131, National Center for Research Resources Biomedical Informatics Research Network Grant U24 RR021760, and NIAAA Integrative Neuroscience Initiative on Alcoholism Grants U01AA13499 and U24AA13513. We are grateful to Dr. Heather Cameron for help with radioimmunoassay. *K.M. and R.-M.K. contributed equally to this work.

Correspondence should be addressed to Andrew Holmes, Section on Behavioral Science and Genetics, Laboratory for Integrative Neuroscience, National Institute on Alcohol Abuse and Alcoholism, 5625 Fishers Lane, Room 2N09, Rockville, MD 20852-9411. E-mail: holmesan@mail.nih.gov.

D01:10.1523/JNEUROSCI.5017-09.2010

Copyright $\odot 2010$ the authors $\quad 0270-6474 / 10 / 305357-11 \$ 15.00 / 0$
}

siderably across individuals; even similar stressors can increase risk for different neuropsychiatric states in different people (Yehuda and LeDoux, 2007). This variation in the impact of stress is likely to be, in some measure, under the moderating influence of genetic factors (Caspi et al., 2010).

Despite being the subject of enormous research efforts, genetic influences and their effects on the neurobiology of stress and emotion-mediating circuits are not yet fully understood. This is in part because of the complexity associated with myriad genetic and environmental factors in human populations. As an alternative approach, rodents provide important model systems for studying the pathophysiology of stress-related neuropsychiatric disease (Cryan and Holmes, 2005). Of considerable value in this regard are isogenic inbred mouse strains.

A panel of different mouse strains represents a significant but restricted degree of genetic diversity in which environmental variance can be carefully controlled. Previous studies have found 
differences in various "emotion-related" phenotypes across inbred strains. This includes marked variation in anxiety-like behavior, although differences between specific strains appear to be contingent on the behavioral task employed, consistent with the significant heterogeneity of rodent anxiety tasks (Turri et al., 2001; Ponder et al., 2007; Brigman et al., 2009; Milner and Crabbe, 2008). Earlier work also indicates that inbred strains differ in their response to stress as measured by various neural, neuroendocrine, and behavioral endpoints. For example, acute stress typically produces heightened anxiety-like behavior and hypothalamic-pituitary-adrenal (HPA)-axis activation in some strains (e.g., BALB/cJ, DBA/2J), but less so in others (e.g., C57BL/6J) (Belzung and Griebel, 2001; Jacobson and Cryan, 2007; Millstein and Holmes, 2007). Relatively few studies have examined strain differences in response to repeated stress (e.g., Pothion et al., 2004; Anisman and Matheson, 2005; Mineur et al., 2006). Such studies are of critical relevance to human stress-related disorders, which are commonly associated with a history of repeated trauma (Berton and Nestler, 2006; Yehuda and LeDoux, 2007).

Here, we first surveyed a panel of seven inbred strains for anxiety- and depression-related behaviors, and HPA-axis phenotypes at baseline and after repeated restraint stress. Subsequent analysis focused on two inbred strains (C57BL/6J and DBA/2J) exhibiting divergent trait and stress-induced anxiety-like phenotypes in the dark/light exploration test (confirmed in the elevated plus maze). To identify genes associated with this strain-stress interaction, we performed gene expression analysis in amygdala, ventromedial prefrontal cortex (vmPFC), and hippocampus. Prominent among the expression changes were glutamatergic genes. Therefore, we next tested for strain differences in stressinduced alterations in amygdala NMDA receptor (NMDAR)mediated excitatory neurotransmission and metaplasticity (temporal summation of NMDAR currents). To establish a causative link between glutamate function and stress effects on anxiety-related behavior, we tested whether stress effects were altered by deletion of either NMDAR NR2A or AMPA receptor (AMPAR) GluR1 subunits. Because stress-induced increases in dendritic length and spine density in basolateral amygdala (BLA) neurons is posited to be a neuronal correlate of changes in behavior (Vyas et al., 2006), we also quantified BLA neuronal dendritic morphology and spine density in NR2A-/- mice.

\section{Materials and Methods}

Subjects. The initial strain survey comprised 129S1/SvImJ (129S1), A/J, $\mathrm{BALB} / \mathrm{cJ}, \mathrm{BALB} / \mathrm{cByJ}, \mathrm{C} 57 \mathrm{BL} / 6 \mathrm{~J}, \mathrm{DBA} / 2 \mathrm{~J}$, and FVB/NJ. These were selected on the basis of (1) their frequent use in behavioral neuroscience and as genetic backgrounds for mouse mutant lines; (2) inclusion as "group A" priority strains in the Mouse Phenome Project, an international effort to provide the biomedical research community with phenotypic data on the most commonly used mouse strains (www.jax.org/phenome); (3) prior studies demonstrating differential trait fear-, anxiety-, and depressionrelated and stress-sensitivity phenotypes (see Introduction); and (4) their use as parental strains in several sets of recombinant inbred strains, including the AXB, BXA, CXB, and BXD sets (see www.genenetwork.org).

All mice were males obtained from The Jackson Laboratory (as in Millstein et al., 2006) to reduce a potential source (i.e., supplier) of genetic and behavioral variation. Mice were aged 8 to 9 weeks at the start of the study, housed two per cage (by strain and stress condition), with cages placed side by side in a temperature-controlled $\left(72 \pm 5^{\circ} \mathrm{F}\right)$ and humidity-controlled ( $45 \pm 15 \%)$ vivarium under a $12 \mathrm{~h}$ light/dark cycle (lights on 6:00 A.M.). Testing was conducted in a manner counterbalanced for strain and stress condition. The number of mice used is given in the figure legends. All experimental procedures were approved by the National Institute on Alcohol Abuse and Alcoholism Animal Care and Use Committee and the local Animal Care and Use Committees, and followed the National Institutes of Health guidelines outlined in "Using Animals in Intramural Research."

Stressor. Ten days of immobilization in "immobilization bags" produces significant alterations in dendritic arborization and/or spine density in the vmPFC, BLA, and CA3 region of the hippocampus in rats and mice (see Holmes and Wellman, 2009; Roozendaal et al., 2009). We adopted a modified version of this protocol in which mice were placed in ventilated 50 $\mathrm{ml} \mathrm{Falcon}$ tubes for $2 \mathrm{~h}$ per day (10:00 A.M. to 12:00 P.M.) for 10 consecutive days. We reasoned that restraint in tubes would be a less severe stressor than restraint in immobilization bags and would therefore allow us to better detect differential sensitivity to restraint across strains than a severe stressor that might cause profound changes (i.e., "floor effect") in all strains. Nonrestrained mice remained in the home cage (Vyas et al., 2002).

Tests for anxiety-related behavior. Twenty-four hours after the final stress, mice were tested for anxiety-like behavior using the light/dark exploration test. We employed this task rather than other commonly used tests for anxiety-like behavior for a number of reasons. First, under baseline conditions in our laboratory, C57BL/6J typically display lesser anxiety-like behavior in this test $[\sim 25 \%$ time out of shelter (e.g., this study) $]$ than in the elevated plus maze $[\sim 10 \%$ open-arm time (e.g., Norcross et al., 2008)]. Therefore, it seemed less likely that a high baseline anxiety-like behavior would preclude us from detecting stress-induced increases in anxiety in this test. We conducted a relatively long (15 min) test to capture the most anxiety-sensitive period during the first $5 \mathrm{~min}$ and dissociate this from general changes in locomotion, as measured by behavior during the final $5 \mathrm{~min}$. A second reason is that the light/dark exploration test has previously demonstrated utility as an assay for uncovering gene expression differences underlying mouse strain differences in basal anxiety-like behavior (Hovatta et al., 2005).

Mice were placed in an opaque black Plexiglas shelter $(39 \times 13 \times 16$ $\mathrm{cm})$ with a $13 \times 8 \mathrm{~cm}$ aperture at floor level that opened onto a large white Plexiglas square arena $(39 \times 39 \times 35 \mathrm{~cm})$ illuminated to $\sim 90$ lux. This apparatus is a $2 / 3$ light versus $1 / 3$ dark design, as used in the original validated formulation of the task (Crawley, 1981) rather than the half light versus half dark design we have used in some previous studies and found to be relatively insensitive to strain differences likely because of its less "stressful" nature. Latency to first exit the shelter, the number of shelter exits (defined as all four paws out of the shelter), and time spent out of the shelter in the open field over a $15 \mathrm{~min}$ session were recorded by an observer using Hindsight (Scientific Programming Services). To dissociate the anxiety-related and general exploratory phases of the test session, data were separately analyzed during the first $5 \mathrm{~min}$ and last 5 min, respectively. The effects of strain and stress were analyzed using two-factor ANOVA followed by Newman-Keuls post hoc tests. Given the high number of strains tested and the resultant reduction of power in our analysis, we conducted planned post hoc comparisons of strain and/or stress effects in the presence of significant ANOVA main effects regardless of whether a significant strain-stress interaction effect was also found. Statistical significance for this and all other analyses was $p \leq 0.05$.

To test whether trait- and/or restraint-induced changes in anxiety-related behavior observed in DBA/2J and C57BL/6J in the light/dark exploration test (see Results) extended to another test for anxiety-like behavior, we assessed baseline and postrestraint behavior in these two strains in the elevated plus maze. The apparatus consisted of two open arms $(30 \times 5 \mathrm{~cm}$; $90 \mathrm{lux})$ and two closed arms $(30 \times 5 \times 15 \mathrm{~cm} ; 20$ lux $)$ extending from a $5 \times 5 \mathrm{~cm}$ central area and elevated $47 \mathrm{~cm}$ from the ground (San Diego Instruments), as described previously (Hefner and Holmes, 2007). The walls were made from black ABS (acrylonitrile butadiene styrene) plastic and the floor from white ABS plastic. A $0.5 \mathrm{~cm}$ raised lip around the perimeter of the open arms prevented mice from falling off the maze. The mouse was placed in the center facing an open arm and allowed to explore the apparatus for $6 \mathrm{~min}$. Time spent in the open arms, entries into the open and closed arms, and head dipping (exploratory movement of head/shoulders over the sides of the open arms) (Holmes and Rodgers, 2003) were recorded by an observer using Hindsight. The mouse was adjudged to be in an arm when all four paws were in an arm. HPA-axis activation after elevated plus-maze exposure was measured by killing mice 30 min after testing (1:00 to 3:00 P.M.) for corticosterone analysis (as described below). Planned $t$ test comparisons were conducted to examine strain differences and stress effects within each strain. 
Stress-induced changes in body weight. We evaluated whether strain differences in stress-responsivity extended to depression-related phenotypes. As a systemic marker of the efficacy of repeated restraint as a stressor, we measured restraint-induced reductions in body weight in the seven inbred strains (Willner et al., 1996; Pothion et al., 2004; Krishnan et al., 2007; Shansky et al., 2009). Changes in body weight over the $10 \mathrm{~d}$ restraint period were compared between restrained and nonrestrained groups and analyzed using two-factor (strain by restraint) ANOVA followed by Newman-Keuls post hoc tests.

Forced swim test depression-related behavior. We used the forced swim test (FST) to measure depression-related behavior (Porsolt et al., 1977; Cryan and Holmes, 2005), conducting this assay $24 \mathrm{~h}$ after the light/dark exploration test. Mice were gently lowered into a transparent Plexiglas cylinder $\left(20 \mathrm{~cm}\right.$ diameter) filled halfway with water $\left(24 \pm 1^{\circ} \mathrm{C}\right)$ for a $6 \mathrm{~min}$ session, as described previously (Boyce-Rustay and Holmes, 2006). The presence/absence of immobility (cessation of limb movements except minor involuntary movements of the hind limbs) was scored using an instantaneous sampling technique every $5 \mathrm{~s}$ from 125 to $360 \mathrm{~s}$ and was expressed as a percentage of the total observations. The effects of strain and restraint were analyzed using two-factor ANOVA followed by Newman-Keuls post hoc tests.

Stress-induced corticosterone. To assess HPA-axis activation induced by swim stress, mice were returned to the home cage after FST and were killed 30 min later via rapid cervical dislocation and decapitation to collect trunk blood samples for serum corticosterone analysis. An additional set of experimentally naive mice were killed at the same time to provide a baseline measure of corticosterone. Samples were taken between 10:00 A.M. and 12:00 P.M. Blood samples were centrifuged at $13,000 \mathrm{rpm}$ for $30 \mathrm{~s}$. Serum was extracted and assayed for total corticosterone (bound and free) using the Coat-a-Count RIA TKRC1 kit (limit of detection: $5.7 \mathrm{ng} / \mathrm{ml}$; Diagnostic Products) as described previously (Boyce-Rustay et al., 2007). For HPA-axis activation after elevated plusmaze exposure, trunk blood was collected $30 \mathrm{~min}$ after testing and centrifuged at $3500 \mathrm{rpm}$ for 1-2 min. Serum was extracted and assayed for total corticosterone (bound and free) using the ImmuChem Double Antibody 125I RIA kit (MP Biomedicals). The effects of strain and restraint were analyzed using two-factor ANOVA followed by Newman-Keuls post hoc tests.

Genome-wide analysis of basal and stress-induced corticolimbic gene expression. Microarray assays were conducted on tissue from three key corticolimbic regions mediating stress and anxiety (amygdala, vmPFC, hippocampus) in DBA/2J and C57BL/6J at baseline and after stress. After removal, brains were stored in RNAlater (Ambion). The vmPFC, amygdala (principally the basolateral nucleus), and whole hippocampus were microdissected within $48 \mathrm{~h}$ of brain collection. The brain was placed in a coronal matrix and sectioned $1.4-2.4 \mathrm{~mm}$ from bregma to obtain the vmPFC (tissue medial to the forceps minor, mainly comprising the infralimbic and prelimbic cortices), and 1.0-2.0 mm caudal to bregma to obtain the amygdala and hippocampus. The amygdala was visualized under a dark-field microscope and dissected using the external and internal capsules as a guide to obtain the basolateral nucleus (although we cannot exclude some inclusion of tissue from the central nucleus and striatum). The whole hippocampus was then dissected.

Tissue was immediately frozen and stored at $-80^{\circ} \mathrm{C}$. Samples from each mouse were stored and analyzed separately (i.e., no pooling). Total RNA was isolated using RNAqueous Micro kit (Ambion). RNA purity and concentration was evaluated with a spectrophotometer using a 260/ $280 \mathrm{~nm}$ absorbance ratio, and RNA quality was checked using Agilent Bioanalyzer 2100 (Agilent Technologies). Samples were processed according to the manufacturer's instructions and hybridized onto Illumina Mouse-6.1 arrays (Illumina). Samples from each strain, stress condition, and brain region were balanced across arrays on a slide to avoid batch confounds. Three biological replicates for each brain region, strain, and treatment group were performed. For each of the two strains, there were two stress conditions and three brain regions (a total of 36 arrays). The number of arrays used meant that we did not perform technical replicates. Instead, we relied on real-time (RT)-PCR confirmation to validate specific expression differences (and then physiological and gene mutant experiments to establish specific functional links).

Raw microarray data were normalized using rank invariant and background subtraction protocols provided by the Illumina BeadStation soft- ware suite. We log-transformed the expression values and stabilized the variance of each array. We extensively reannotated these probes on the array, and the improved annotations were incorporated into the data analysis for the current study. The custom annotation for the Illumina Sentrix MouseWG-6 v1.1 is available at www.genenetwork.org/share/. The Illumina array contains over 46,000 probes, and these were initially filtered by expression; i.e., expression signals below background in half or more of the samples were excluded, resulting in 25,908 probes for analyses. A false discovery rate was not applied because this proved overly stringent to detect effects of stress and therefore likely produced false negatives. Instead, we applied a combined criterion for true positive expression differences of a fold difference $\geq 1.3$ and a statistically reliable difference ( $p<0.01, t$ test). Baseline strain effects were defined as gene expression values in nonstressed C57BL/6J compared to values in nonstressed DBA/2J. Stress effects were defined as gene expression values in stressed versus nonstressed mice of the same strain. Functional categorization and enrichment analysis of these genes was done using DAVID (http://david.abcc.ncifcrf.gov).

Real-time PCR confirmation of gene expression. To verify gene expression differences, we performed quantitative RT-PCR analysis on 15 genes that met the criteria of statistical reliability $(p \leq 0.01)$ and 1.3 -fold or greater gene expression difference. Eight genes (Gal, Atpla2, Bdnf, Nr4a2, Chrna4, Comt, Drdla, and Rgs2) have previously been linked to anxiety- and stress-related behaviors (for references, see Discussion). Four genes (Grik1, Grin1, Grial, and Homer1) are mediators of glutamate neurotransmission and neural plasticity (for references, see Discussion). Three genes (Per1, Per2, and Dbp) are circadian genes (for references, see Discussion).

cDNA was synthesized using a first-strand cDNA kit (GE Healthcare) according to manufacturer's protocol. Primers for RT-PCR were designed based on available sequences using the ProbeFinder software (Roche Diagnostics). The ProbeFinder software combines a suitable Universal Library probe (Roche Diagnostics) with a set of gene-specific PCR primer pairs. All primer pairs were checked by an in silico PCR algorithm that searches the relevant genome and transcriptome and flags any possible mispriming sites that could lead to nonspecific amplification. The assays were chosen to be as close as possible to the Illumina probe targets, and to span exons to avoid amplification of trace genomic DNA. To assess amplification efficiency, standard dilution curves were generated for all genes. Low-efficiency assays were excluded. Two microliters of cDNA were added to a PCR reaction mix containing $0.2 \mu \mathrm{l}$ of forward and reverse primers ( $20 \mathrm{~mm}), 0.1 \mu \mathrm{l}$ of probe $(10 \mathrm{~mm}), 5 \mu \mathrm{l}$ of 2X LC480 master mix (Roche), and $2.7 \mu \mathrm{l}$ of DNase free water. PCR was performed using the Roche LightCycler 480 system.

PCR amplification for each gene was conducted in technical duplicates and three biological replicates. The threshold cycle (Ct) of technical duplicates was then averaged. All expression values were normalized to the expression of cyclophilin D, as this gene showed no expression difference among the different RNA samples. Relative differences in RNA abundance among the different strains and treatment groups were then determined by comparing the normalized Ct values (Livak and Schmittgen, 2001). On determining polarity (upregulation or downregulation) of the effect of strain or stress, one-tailed Student's $t$ tests were used to test for statistical significance.

Amygdala NMDAR neuronal signaling and metaplasticity. We next tested for BLA glutamate function at the neuronal level by measuring NMDAR-mediated evoked EPSCs (eEPSCs) using ex vivo whole-cell voltage-clamp recordings. Mice were subjected to repeated restraint (as above) and were then, $24 \mathrm{~h}$ after the final restraint, killed via rapid decapitation under isoflurane anesthesia, along with a set of nonrestrained mice. Brains were quickly removed and placed in ice-cold sucrose artificial CSF [ACSF; containing the following (in mM): 194 sucrose, $20 \mathrm{NaCl}, 4.4 \mathrm{KCl}, 2 \mathrm{CaCl}$, $1 \mathrm{MgCl} 2,1.2 \mathrm{NaH}_{2} \mathrm{PO}_{4}, 10.0$ glucose, and $26.0 \mathrm{NaHCO} 3$, saturated with $\left.95 \% \mathrm{O}_{2} / 5 \% \mathrm{CO}_{2}\right]$. Threehundred-micrometer slices were sectioned on a vibratome and transferred to a submerged recording chamber and perfused with heated $\left(26^{\circ} \mathrm{C}\right.$, unless otherwise stated), oxygenated ACSF at a rate of $\sim 2 \mathrm{ml} / \mathrm{min}$. Additional slices were stored in a heated $\left(\sim 28^{\circ} \mathrm{C}\right)$ and oxygenated $(95 \%$ $\mathrm{O}_{2} / 5 \% \mathrm{CO}_{2}$ ) holding chamber containing "normal" ACSF [containing the following (in mM): $124 \mathrm{NaCl}, 4.4 \mathrm{KCl}, 2 \mathrm{CaCl} 2,1.2 \mathrm{MgSO}_{4} 1$ $\mathrm{NaH}_{2} \mathrm{PO}_{4}, 10.0$ glucose, and 26.0 NaHCO3] for later use. Slices equili- 
brated in normal ACSF for $1 \mathrm{~h}$ before recording and were then submerged in the recording chamber (Warner Instruments). Neurons of the BLA were directly visualized with infrared video microscopy. Recording electrodes (3-6 M $\Omega$ ) were pulled on a Flaming-Brown Micropipette Puller (Sutter Instruments) using thin-walled borosilicate glass capillaries. Recording electrodes were filled with the following (in $\mathrm{mm}$ ): 135 $\mathrm{Cs}^{+}$-gluconate, $5 \mathrm{NaCl}, 10$ HEPES, 0.6 EGTA, 4 ATP, $0.4 \mathrm{GTP}$, and 290-295 mOsmol. Signals were acquired via a Multiclamp 700B amplifier (Molecular Devices) and digitized and analyzed via pClamp 9.2 software (Molecular Devices).

NMDAR-mediated eEPSCs were evoked with bipolar Ni-chrome stimulating electrodes placed locally within the BLA, $100-500 \mu \mathrm{m}$ dorsal from the recorded neuron. Electrical stimulation $(5-40 \mathrm{~V}, 100-150 \mu \mathrm{s}$ duration) was applied at $0.2 \mathrm{~Hz}$ unless stated otherwise. NMDAR-mediated eEPSCs were pharmacologically isolated from $\mathrm{GABA}_{\mathrm{A}} \mathrm{R}$ - and AMPARmediated currents by adding $25 \mu \mathrm{m}$ picrotoxin and $10 \mathrm{~mm} \operatorname{NBQX}(2,3-$ dihydroxy-6-nitro-7-sulfonyl-benzo[f]quinoxaline), respectively, and recording at a holding potential of $+40 \mathrm{mV}$. Input resistance, holding current, and series resistance were monitored continuously during recording. Experiments in which changes in series resistance were $>20 \%$ were excluded from the data analysis.

Twenty traces $(5 \mathrm{~min}$ ) were averaged to obtain a baseline eEPSC. eEPSC decay was fitted with two exponentials $(\tau 1$ and $\tau 2)$ using Clampfit 9.2 software (Molecular Devices) from trace normalized average traces. To directly compare decay times between experimental conditions, the two decay time components, $\tau 1$ and $\tau 2$, were combined into a weighted time constant, $t w$, using the equation: $t w=(\tau 1 * a 1)+(\tau 2 * a 2)$, where $a 1$ and $a 2$ are the relative amplitudes of the two exponential components. Next, to evaluate temporal summation of eEPSCs (Philpot et al., 2001), we delivered a train of 10 pulses at the stated frequency. These data were analyzed by averaging traces from the same frequency, normalizing the averaged trace to the peak of the first eEPSC pulse and then measuring the normalized peak amplitude at the subsequent nine pulses. Statistical analyses were performed using Microsoft Excel, GraphPad Prism, and Microcal Origin. The effects of strain and stress on weighted $\tau$ were analyzed using a two-factor ANOVA. The effects of strain, stress, and pulse number at each stimulation intensity were analyzed using three-factor ANOVA, with repeated measures for pulse number, followed by Newman-Keuls post hoc tests.

Stress in NR2A and GluR1 null mutants. Our gene expression analysis found that stress altered amygdala expression of glutamate receptors, including NMDA NR1 (Grin1), in C57BL/6J and not DBA/2J. Constitutive null mutation of NR1 subunit is lethal. NR2A is a modulatory NMDAR subunit highly expressed in the amygdala and linked previously to anxiety-like behavior (Boyce-Rustay and Holmes, 2006; Cryan and Dev, 2007). We tested whether NR2A was necessary for stress-induced changes in anxiety-like behavior (as above) in constitutive NR2A (Grin2a) null mutants on a C57BL/6J genetic background. Grin2a null mutants were generated and backcrossed to C57BL/6J congenicity as described previously (Sakimura et al., 1995; Brigman et al., 2008). Grin $2 a-1-$ and Grin $2 a+1+$ littermates were subjected to repeated stress and tested in the light/dark exploration test $24 \mathrm{~h}$ later, as above.

Although C57BL/6J had higher hippocampal expression of AMPA GluR1 than DBA/2J under nonstressed conditions, this receptor was not altered by stress. We tested whether GluR1 was unnecessary for stressinduced changes in anxiety-like behavior (as above) in constitutive GluR1 (Gria1) null mutant mice on a C57BL/6J genetic background. Gria1 null mutants were generated and backcrossed to C57BL/6J congenicity as described previously (Zamanillo et al., 1999; Wiedholz et al., 2008). Gria1-/- and Gria1+/+ littermates were subjected to repeated stress and tested in the light/dark exploration test $24 \mathrm{~h}$ later, as above. This was the only experiment in which we used both males and females (because of low availability); statistical analyses found no effect of genotype and no interaction between sex and genotype or stress.

NR2A null mutant amygdala neuronal dendritic morphology and spine density. Test naive mice were overdosed with urethane and transcardially perfused with saline. Brains were removed and processed for Golgi histology using a modification of Glaser and Van der Loos' (1981) Golgi stain as described previously (Wellman et al., 2007). Coronal sections were cut at $160 \mu \mathrm{m}$ on a sliding microtome (American Optical 860).
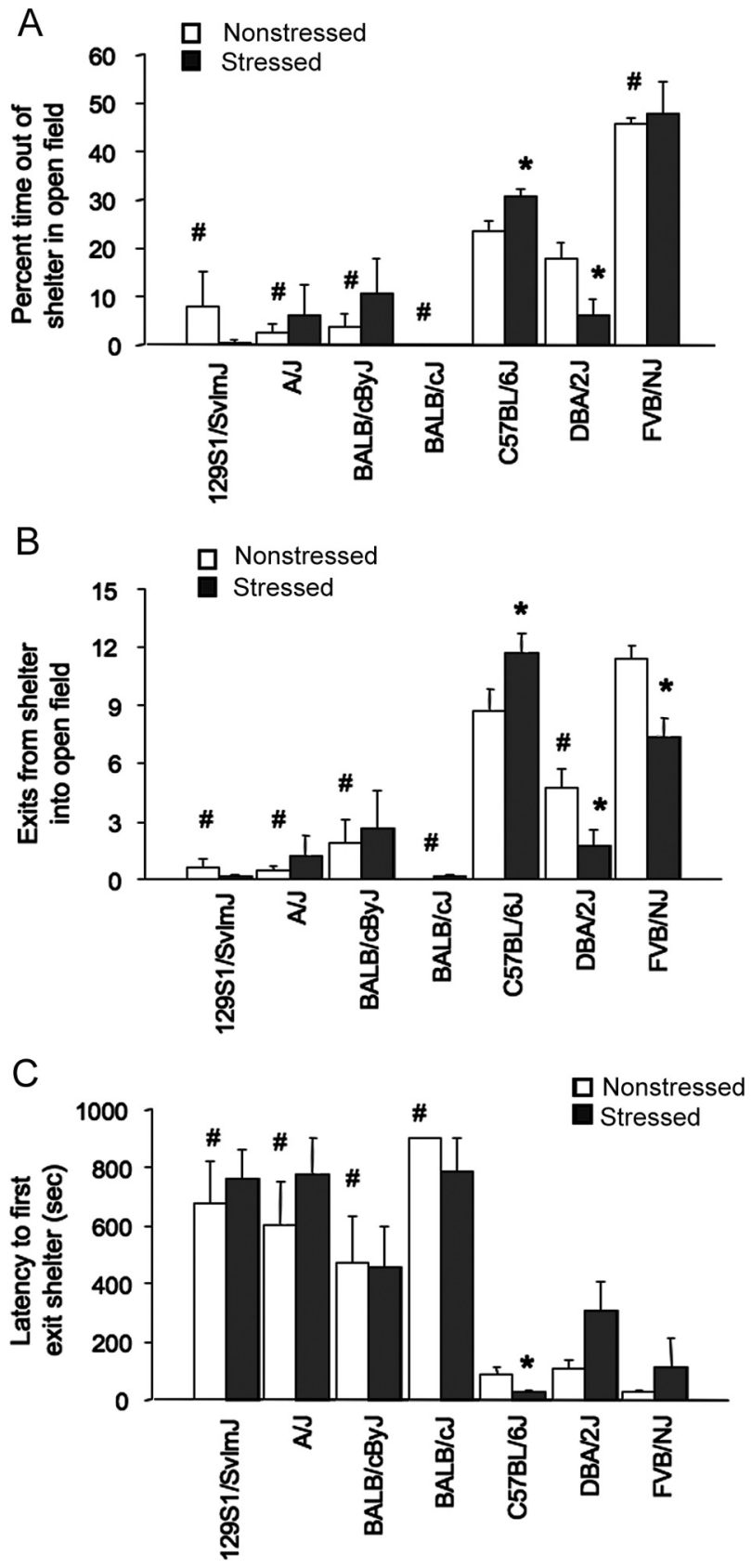

Figure 1. Basal and poststress anxiety-like behavior in seven strains. $A$, Stressed DBA/2J spent less time, whereas $(57 B L / 6)$ spent more time, out of the shelter than nonstressed controls in the light/ dark exploration test. All strains except FVB/NJ and DBA/2J spent less time out of the shelter than C57BL/6J under nonstressed conditions. B, Stressed DBA/2J and FVB/NJ made fewer shelter exits, whereas $[57 \mathrm{BL} / 6 \mathrm{~J}$ made more exits than nonstressed controls. Under nonstressed conditions, all strains except FVB/NJ made fewer shelter exits than C57BL/6J. C, Stressed C57BL/6J had a lower latency to exit shelter than nonstressed controls. Under nonstressed conditions, all strains except $\mathrm{FVB} / \mathrm{NJ}$ and DBA/2J showed a longer latency to first exit the shelter than $\mathrm{C} 57 \mathrm{BL} / 6 \mathrm{~J} . n=7-10$ per strain under stress. Data are expressed mean \pm SEM. ${ }^{*} p<0.05$ versus nonstressed/same strain; ${ }^{\#} p<0.05$ versus nonstressed $(57 \mathrm{BL} / 6 \mathrm{~J}$.

Free-floating sections were then alkalinized, developed, fixed, dehydrated, mounted, and coverslipped.

Analysis of BLA pyramidal neurons was restricted to locations between 0.8 and $2.0 \mathrm{~mm}$ posterior to bregma. Within this region, the BLA is readily identified in Golgi-stained material, as the external capsule branches into two smaller fiber tracts that define the dorsal, medial, and lateral borders of the BLA. Likewise, axon fibers clearly delineate the basal amygdala from the BLA. Pyramidal neurons within the BLA were defined 

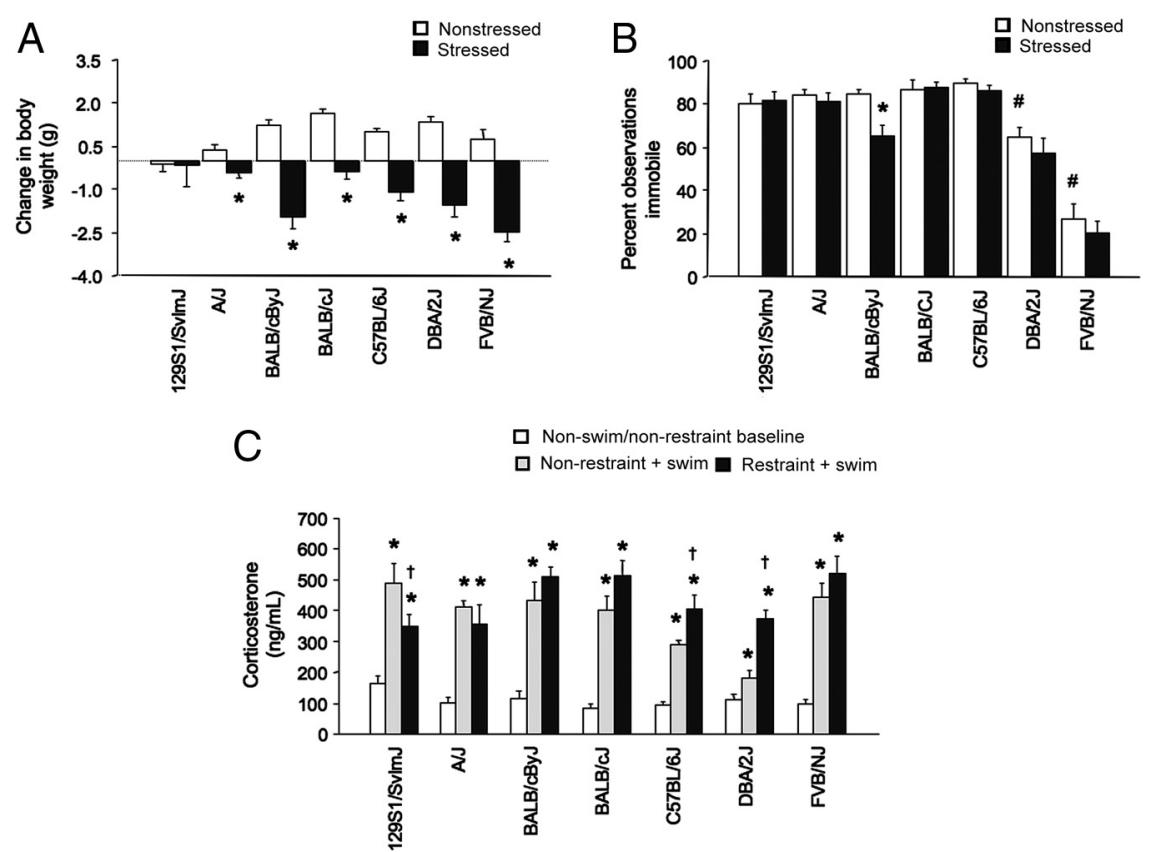

Figure 2. Basal and stress-induced depression-related phenotypes in seven strains. $A$, Repeated stress reduced body weight, relative to nonstressed controls over the same period, in all strains except $12951 /$ SvImJ $\left(n=5-20\right.$ per strain under stress) $\left({ }^{*} p<\right.$ 0.05 vs nonstress/same strain). $\boldsymbol{B}, \mathrm{BALB} / \mathrm{cByJ}$, but no other strain, showed less immobility after stress compared to no stress. Under nonstressed conditions, DBA/2J and FVB/NJ were more mobile than C57BL/6J ( $n=7-9$ per strain under stress; ${ }^{*} p<0.05$ vs nonstressed BALB/CByJ; ${ }^{\#} p<0.05$ vs nonstressed (57BL/6J). C, Regardless of prior restraint stress, swim stress increased serum corticosterone levels in all strains, relative to nonswim/nonrestrained controls ( ${ }^{*} p<0.05$ vs nonrestrained/same strain). Restraint stressed $\mathrm{C57BL} / 6 \mathrm{~J}$ and DBA/2J had a higher swim-stress-induced corticosterone response than nonrestrained counterparts. Restrained $12951 / \mathrm{SvlmJ}$ had a lower swim-stress-induced corticosterone response than nonrestrained counterparts $\left({ }^{\dagger} p<0.05 \mathrm{vs}\right.$ nonrestrained/swim stressed/same strain; $n=5-15$ per strain under stress). Data are expressed as mean \pm SEM.

by the presence of a distinct, single apical dendrite, two or more basilar dendritic trees extending from the base of the soma, and dendritic spines. Neurons selected for reconstruction were located in the middle third of the section, did not have truncated branches, and were not obscured by neighboring neurons and glia, with dendrites that were easily discriminable by focusing through the depth of the tissue. Within each region examined, 10 neurons were drawn for each mouse. Neurons were drawn at $600 \times$, and morphology was quantified in three dimensions using a computer-based neuron-tracing system (Neurolucida; MBF Bioscience) with the experimenter blind to genotype. Total length and number of dendrites, as well as the length and number of terminal branches, were measured. To assess differences in the amount and location of dendritic material, a three-dimensional version of a Sholl analysis (Larkman, 1991) was performed in which the number of intersections of dendrites with $10 \mu \mathrm{m}$ concentric spheres centered on the soma was measured. For statistical and graphical purposes, counts of intersections were summed over pairs of radii.

Spines were counted on dendritic branches from 10 neurons per mouse. Spines were counted on first- through fourth-order branches, as these make up $\sim 90 \%$ of the dendritic arbor of BLA pyramidal neurons. For each neuron, one dendritic tree containing at least one third-order branch was chosen. One to two branches at each order were drawn and spines counted at $1000 \times$ using a computer-based neuron-tracing system (Neurolucida; MBF Bioscience). Branches sampled averaged 10.49 $\pm 0.65,45.48 \pm 2.16,57.15 \pm$ 3.56 , and $62.23 \pm 3.30 \mu \mathrm{m}$ for first- through fourth-order dendrites, respectively. Spines were identified based on morphological criteria for "mushroom" and "thin" spines (Peters and Kaiserman-Abramof, 1970); only protrusions perpendicular to the dendritic shaft and possessing a clear neck and bulbous head were counted. Because spine density varies with branch order, the lengths of dendritic segments were recorded, and spine densities (spines per $10 \mu \mathrm{m}$ ) for each branch order were calculated separately.

The effect of genotype on dendrite length and number was analyzed using $t$ tests. The effects of genotype by distance from soma on amount and location of dendritic material, and the effects of genotype by branch order on dendritic spine density, were analyzed using two-factor ANOVAs with repeated measures for distance and branch order, respectively.

\section{Results}

\section{Stress effects on anxiety-related} behavior

In the light/dark exploration test, there was a significant effect of strain $\left(F_{(6,102)}=\right.$ 31.73; $p<0.01)$, but no main effect of stress or a strain-stress interaction, for time out of the shelter. Despite the absence of an interaction effect, our a priori hypothesis that strains would differ in their response to stress led us to perform post hoc comparisons between stressed and nonstressed groups. DBA/2J spent significantly less time out of the shelter than nonstressed controls (Fig. $1 \mathrm{~A}$ ). Conversely, stressed C57BL/6J spent significantly more time out of the shelter than nonstressed C57BL/6J (Fig. 1A). Under nonstressed conditions, 129S1, A/J, BALB/ cByJ, and BALB/cJ spent significantly less time, and $\mathrm{FVB} / \mathrm{NJ}$ spent more time, out of the shelter than C57BL/6J.

There was also a significant strain-restraint stress interaction $\left(F_{(6,102)}=3.21 ; p<0.01\right)$ for shelter exits during the first $5 \mathrm{~min}$. Post hoc analysis showed that stressed DBA/2J and FVB/NJ made significantly fewer exits than nonstressed DBA/2J and FVB/NJ controls, whereas stressed C57BL/6J made significantly more exits than C57BL/6J controls (Fig. 1 B). 129S1, A/J, BALB/cByJ, and BALB/cJ showed no change in shelter exits after stress, likely because of low shelter exits under nonstressed conditions, where all strains except FVB/NJ made significantly fewer exits than C57BL/6J.

There was a significant effect of strain $\left(F_{(6,102)}=19.96 ; p<\right.$ $0.01)$ but not stress, and no strain-stress interaction for latency to first exit the shelter. Planned post hoc comparisons showed that C57BL/6J had a significantly shorter latency to exit than nonstressed counterparts, except FVB/NJ and DBA/2J (Fig. 1C). Nonstressed 129S1, A/J, BALB/cByJ, and BALB/cJ were significantly slower to exit the shelter than nonstressed C57BL/6J.

Stress did not affect any measure during the last $5 \mathrm{~min}$ of the test. There were significant strain effects for shelter exits $\left(F_{(6,102)}=\right.$ 35.02; $p<0.01)$ and time out of the shelter $\left(F_{(6,102)}=52.01 ; p<\right.$ 0.01). On both measures, nonstressed 129S1, A/J, BALB/cByJ, and $\mathrm{BALB} / \mathrm{cJ}$ had lower scores than nonstressed C57BL/6J (data not shown).

In the elevated plus maze, stressed C57BL/6J mice spent a significantly greater percentage of time in the open arms (nonstressed C57BL/6J, $6.9 \pm 1.4 \%$, mean \pm SEM; stressed C57BL/6J, $14.2 \pm 3.0 \%$; nonstressed DBA/2J, $3.3 \pm 1.1 \%$; stressed DBA/2J, $4.3 \pm 1.1 \% ; t=2.33, \mathrm{df}=18, p<0.05, n=8-11$ per strain under stress) and made significantly more open-arm entries (nonstressed C57BL/6J, $3.3 \pm 0.6$; stressed C57BL/6J, $5.2 \pm 0.7$; nonstressed DBA/2J, $1.8 \pm 0.5$; stressed DBA/2J, $2.4 \pm 0.4 ; t=2.11$, $\mathrm{df}=18, p<0.05$ ) and head dips (nonstressed C57BL/6J, $17.6 \pm$ 1.9; stressed C57BL/6J, $25.1 \pm 2.4$; nonstressed DBA/2J, $5.8 \pm$ 1.0; stressed DBA/2J, $6.1 \pm 1.1 ; t=2.46, \mathrm{df}=18, p<0.05)$ than nonstressed C57BL/6J, whereas stress did not affect any of these 
behaviors in DBA/2J. Open-arm time ( $t=$ $3.15 ; \mathrm{df}=35 ; p<0.01)$, open-arm entries $(t=3.41 ; \mathrm{df}=35 ; p<0.01)$ and head dips $(t=7.66 ; \mathrm{df}=35 ; p<0.01)$ were all significantly lower in DBA/2J than C57BL/ $6 \mathrm{~J}$, regardless of stress. There was a nonsignificant trend for more closed-arm entries in stressed relative to nonstressed mice of both strains (nonstressed C57BL/ 6J, $16.4 \pm 0.9$; stressed C57BL/6J, $19.6 \pm$ 1.4 ; nonstressed $\mathrm{DBA} / 2 \mathrm{~J}, 13.0 \pm 0.8$; stressed DBA/2J, $15.4 \pm 1.2$ ). Serum corticosterone levels $30 \mathrm{~min}$ after plus-maze exposure were significantly elevated in stressed DBA/2J compared with nonstressed DBA/2J mice (nonstressed DBA/ 2J, $396 \pm 40 \mathrm{ng} / \mathrm{mL}$; stressed DBA/2J, 645 $\pm 58, t=3.60 ; \mathrm{df}=15 ; p<0.01$ ), but there was no difference between stress groups in C57BL/6J mice (nonstressed C57BL/6J, $412 \pm 22 \mathrm{ng} / \mathrm{mL}$; stressed C57BL/6J, $425 \pm 25)$. Finally, there was a significant effect of stress $\left(F_{(1,32)}=40.81\right.$; $p<0.01$ ), but not genotype, and no interaction for body weight in this cohort. Stress significantly reduced body weight regardless of strain (nonstressed C57BL/ 6J, $0.9 \pm 0.2 \mathrm{~g}$, mean \pm SEM; stressed C57BL/6J, $-0.6 \pm 0.1$; nonstressed DBA/2J, $0.6 \pm 0.3$; stressed DBA/2J, $-1.1 \pm 0.3$ ).

\section{Stress effects on body weight and depression-related behavior}

There was a significant strain-stress interaction for change in body weight over the $10 \mathrm{~d}$ restraint period $\left(F_{(6,123)}=3.87 ; p<\right.$ $0.01)$. Post hoc tests showed that, with the exception of 129S1, all strains had a significant reduction in body weight after restraint compared to the weight gain over the same period in nonstressed mice (Fig. 2A).

There was a significant effect of strain $\left(F_{(6,98)}=58.24 ; p<0.01\right)$ and stress $\left(F_{(1,98)}=5.61 ; p<0.05\right)$, but no strainstress interaction for percentage of immobility in the FST. Planned post hoc analysis found that stressed BALB/cByJ showed significantly less immobility than nonstress BALB/ cByJ counterparts, but no other strain showed a change in behavior after stress (Fig. 2B). Under baseline conditions, $\mathrm{DBA} / 2 \mathrm{~J}$ and $\mathrm{FVB} / \mathrm{NJ}$ showed significantly less immobility than C57BL/6J (Fig. $2 B$ ).

There was a significant stress-strain interaction $\left(F_{(6,152)}=\right.$ 4.82; $p<0.01$ ) for corticosterone levels. Post hoc analysis showed that, regardless of whether mice had been repeatedly restrained, swim stress significantly increased corticosterone in all strains compared to a nonswim/nonrestrained baseline group (Fig. 2C). Moreover, swim stress produced significantly higher corticosterone levels in restrained C57BL/6J and DBA/2J than in nonrestrained counterparts. A maximal ("ceiling") response under nonrestrained conditions may have prevented detection of similar increases in restrained A/J, BALB/cJ, BALB/cByJ, and FVB/NJ. However, contrasting with all other strains, restraint actually produced a blunted corticosterone response to swim stress in $129 \mathrm{~S} 1$.
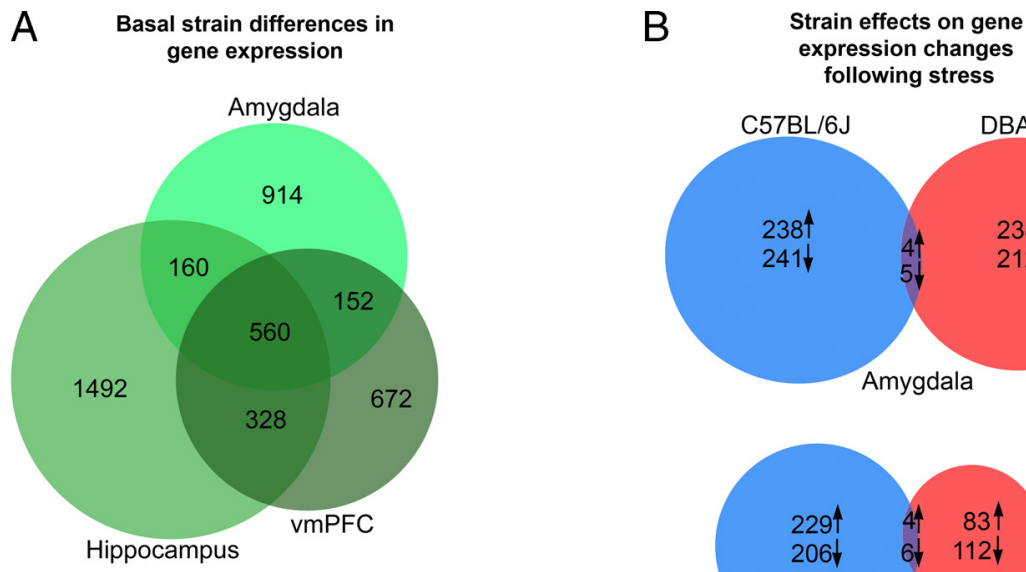

xpression change
following stress
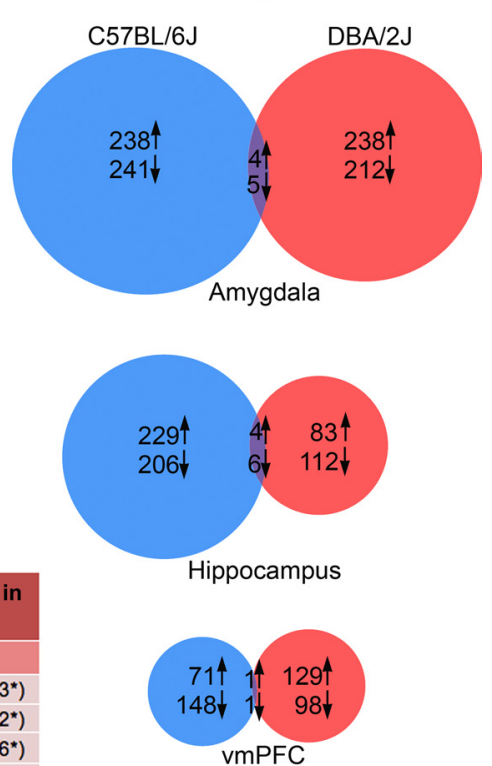

$\uparrow 1.3^{* *}\left(\uparrow 2.4^{* *}\right)$

$\downarrow 2.2^{\star \star}\left(\downarrow 1.3^{\star}\right)$

$\uparrow 1.9^{\star \star}\left(\uparrow 2.2^{\star}\right)$

$\downarrow 2.8^{\star \star}\left(\downarrow 6.6^{\star}\right)$

Hippocampus

\begin{tabular}{|c|c|c|c|}
\hline Atp1a2 & $\uparrow 2.0^{* \star}\left(\downarrow 1.5^{\star \star}\right)$ & - & $\uparrow 2.2^{* *}\left(\downarrow 1.4^{*}\right)$ \\
\hline Bdnf & $\downarrow 1.9^{* \star}\left(\downarrow 1.4^{\star \star}\right)$ & - & $\downarrow 1.6^{* *}(-)$ \\
\hline$D b p$ & - & $\uparrow 1.8^{* \star}\left(\uparrow 2.8^{*}\right)$ & $\uparrow 2.5^{\star \star}(-)$ \\
\hline Gria1 & $\uparrow 1.4^{* \star}\left(\uparrow 1.2^{\star \star}\right)$ & - & $\uparrow 1.4^{\star *}(-)$ \\
\hline Homer1 & - & $\downarrow 1.6^{* \star}\left(\downarrow 1.3^{\star}\right)$ & $\downarrow 2.9^{\star \star}(-)$ \\
\hline $\mathrm{Nr} 4 \mathrm{a} 2$ & - & - & $\downarrow 1.4^{* *}\left(\downarrow 1.4^{* *}\right)$ \\
\hline \multicolumn{4}{|c|}{ Ventromedial prefrontal cortex } \\
\hline Chrna4 & $\uparrow 1.7^{\star \star}\left(\uparrow 1.6^{\star}\right)$ & - & $\uparrow 1.3^{* *}\left(\uparrow 1.7^{\star}\right)$ \\
\hline Comt & $\downarrow 1.6^{* *}\left(\downarrow 1.4^{*}\right)$ & - & $\uparrow 1.3^{* *}(-)$ \\
\hline Drd1a & - & - & $\uparrow 1.4^{* *}\left(\uparrow 1.4^{*}\right)$ \\
\hline Per2 & - & $\uparrow 1.9^{*}\left(\uparrow 1.9^{* *}\right)$ & $\uparrow 2.2^{\star \star}\left(\uparrow 1.7^{\star \star}\right)$ \\
\hline Rgs2 & $\uparrow 1.5^{* *}\left(\uparrow 1.2^{*}\right)$ & $\downarrow 1.3^{* *}(-)$ & - \\
\hline
\end{tabular}

Figure 3. Basal and poststress corticolimbic gene expression in $(57 \mathrm{BL} / 6 \mathrm{~J}$ and DBA/2J. $A$, Basal gene expression differed mark-

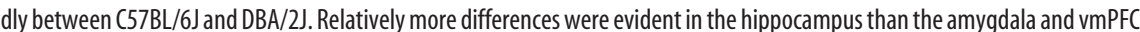
was extensive overlap of differentially expressed genes across the three brain regions. B, C57BL/6J and DBA/2J showed an stress). C, Significant gene expression differences, and confirmation by RT-PCR (in parentheses), are shown. Symbols indicate upregulation $(\uparrow)$, downregulation $(\downarrow)$, and unconfirmed $(-)$. ${ }^{* *} p<0.01 ;{ }^{*} p<0.05$.

\section{Genome-wide corticolimbic gene expression}

Nonstressed DBA/2J and C57BL/6J differentially expressed 1786 transcripts (1524 known genes) in amygdala, 2540 transcripts (2154 known genes) in hippocampus, and 1712 transcripts (1491 known genes) in the vmPFC. A large proportion of the same genes was differentially expressed between strains in either two or all three regions (Fig. 3A). For full list, see supplemental Spreadsheet 1 (available at www.jneurosci.org as supplemental material).

Analyzing the effect of stress as a function of strain, stress produced a similar number of upregulations and downregulations in the amygdala of DBA/2J and C57BL/6J (Fig. 3B). Stress caused twice as many changes in the C57BL/6J than DBA/2J hippocampus (mainly upregulations). C57BL/6J showed more downregulations than upregulations in vmPFC after stress, whereas DBA/2J showed the opposite pattern. For all three regions, very few $(\sim 2 \%)$ of the stress-induced expression changes in $\mathrm{C} 57 \mathrm{BL} / 6 \mathrm{~J}$ and $\mathrm{DBA} / 2 \mathrm{~J}$ involved the same genes.

Functional classification of stress-sensitive genes revealed enrichment in synaptic plasticity (e.g., glutamate receptors) and ion 
A
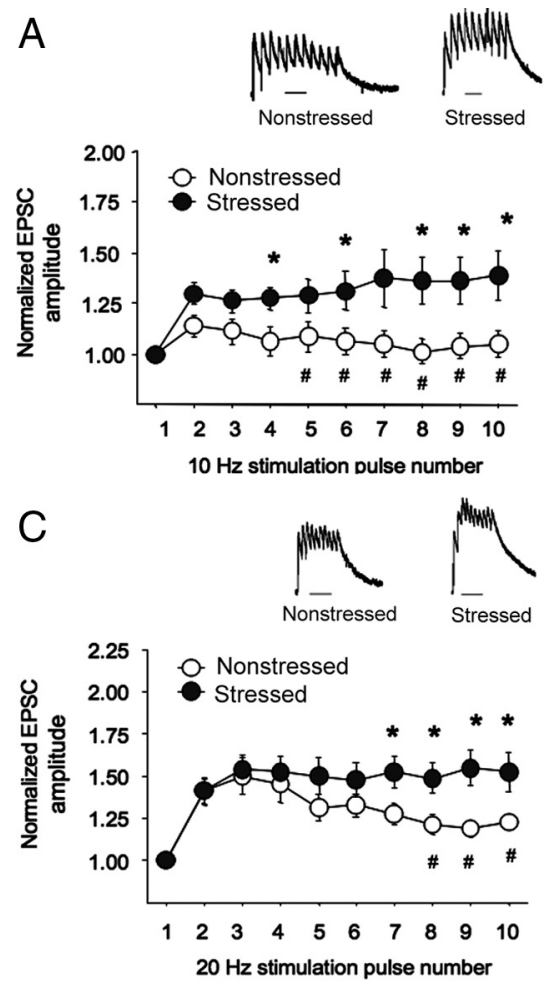

$E$

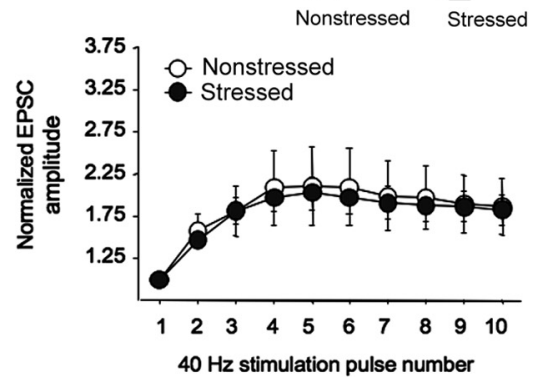

B
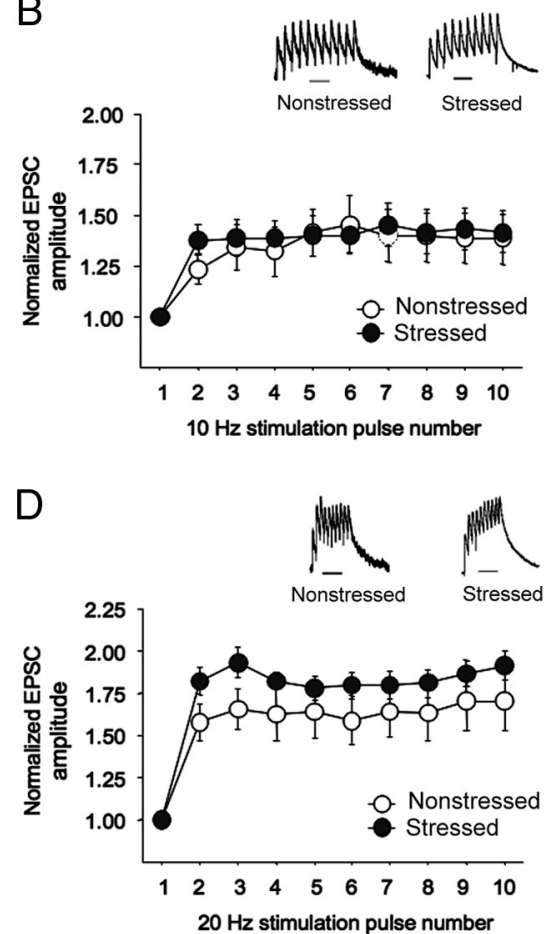

$\mathrm{F}$
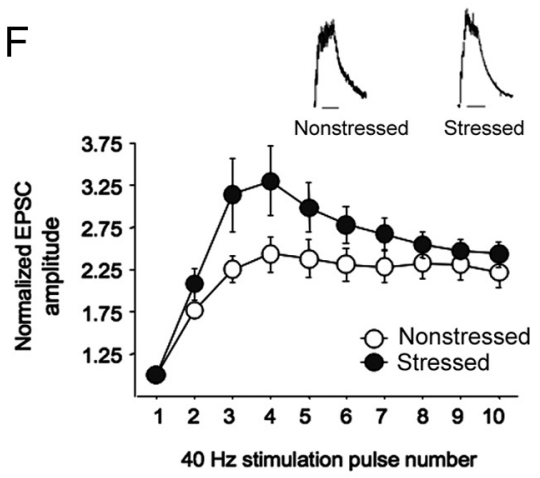

Figure 4. Amygdala NMDAR neuronal signaling and metaplasticity in (57BL/6) and DBA/2J. $\boldsymbol{A}, \boldsymbol{B}$, Measurement of temporal summation of NMDAR EPSCs evoked by $10 \mathrm{~Hz}$ local stimulation showed that stress significantly increased amplitudes in DBA/2J ( $\boldsymbol{A})$ but not C57BL/6J (B). C, D, NMDAR-EPSC amplitudes evoked by $20 \mathrm{~Hz}$ stimulation were significantly increased by stress in DBA/2J (C), but not $(57 \mathrm{BL} / 6 \mathrm{~J}(\boldsymbol{D}) . \boldsymbol{E}, \boldsymbol{F}$, Stress did not alter amplitudes evoked by $40 \mathrm{~Hz}$ stimulation in either strain probably because of saturation. Under nonstressed conditions, amplitude was significantly lower in DBA/2J than C57BL/6J after $10 \mathrm{~Hz}$ (pulses 5-10) and $20 \mathrm{~Hz}$ (pulses $8-10$ ), but not $40 \mathrm{~Hz}$. Data are expressed as mean \pm SEM. Representative traces for each stimulation frequency are depicted (insets) Scale bars, 250 ms. ${ }^{*} p<0.05$ versus the same pulse number in nonstressed DBA/2J; ${ }^{\#} p<0.05$ versus nonstressed $(57 \mathrm{BL} / 6 \mathrm{~J}$ at the same pulse number.

transport genes in $\mathrm{C} 57 \mathrm{BL} / 6 \mathrm{~J}$, and enrichment in genes related to nervous system development, programmed cell death, and myelination in DBA/2J (supplemental Spreadsheet 1, available at www.jneurosci.org as supplemental material).

RT-PCR confirmed significantly lower expression of hippocampal Grial and vmPFC Chrna4 and Rgs2, and higher expression of hippocampal Bdnf and prefrontal Comt, in nonstressed C57BL/6J compared to nonstressed DBA/2J (all $p<0.05$ by $t$ test) (Fig. 3C). In C57BL/6J, stress significantly reduced amygdala expression of Grik1 and Gal, and hippocampal Nr4a2, and increased expression of amygdala Grin1 and vmPFC Chrna4, Drd1 $a$ and Per2. In DBA/2J, stress significantly increased amygdala Per1, hippocampal Dbp and prefrontal Per2, and decreased hippocampal Homer1. Arrays showed higher basal expression and stress-induced upregulation of Atp1a2 in C57BL/6J, whereas

RT-PCR showed the reverse effect, likely because of differentially spliced variants.

Amygdala NMDAR neuronal signaling and metaplasticity

NMDAR-mediated eEPSC decay time (as measured by weighted $\tau$ ) was significantly affected by strain $\left(F_{(1,30)}=23.67 ; p<\right.$ $0.05)$ but not stress, reflecting significantly longer decay time in $\mathrm{DBA} / 2 \mathrm{~J}$ than C57BL/6J, regardless of stress (nonstressed C57BL/6J, $97.1 \pm 5.7$; stressed C57BL/6J, $104.7 \pm 12.5$; nonstressed DBA/2J, $181.6 \pm$ 24.3; stressed DBA/2J, $172.2 \pm 17.2 ; n=$ 6-12 per strain under stress).

There was a significant pulse by strain by stress interaction for normalized eEPSC amplitude at all three stimulation frequencies: $10 \mathrm{~Hz}\left(F_{(8,240)}=2.32 ; p<0.05\right), 20 \mathrm{~Hz}$ $\left(F_{(8,240)}=3.61 ; p<0.01\right)$, and $40 \mathrm{~Hz}$ $\left(F_{(8,240)}=2.31 ; p<0.05\right)$. Post hoc analysis showed that eEPSC amplitude at the lower $(10 \mathrm{~Hz})$ stimulation frequency was unaltered by stress in C57BL/6J, but was significantly increased by stress in $\mathrm{DBA} / 2 \mathrm{~J}$ at later pulses (i.e., 6, 8-10) (Fig. 4A,B). After $20 \mathrm{~Hz}$ stimulation, stress significantly increased amplitudes (pulses 7-10) in DBA/2J, but not C57BL/6J (Fig. 4C,D). Amplitudes were not significantly altered by stress after $40 \mathrm{~Hz}$ stimulation, probably because of saturation (Fig. 4E,F). Under nonstressed conditions, amplitude was significantly lower in DBA/2J than C57BL/6J after $10 \mathrm{~Hz}$ (pulses 5-10) and $20 \mathrm{~Hz}$ (pulses 8-10), but not $40 \mathrm{~Hz}$.

Stress in NR2A and GluR1 null mutants In NR2A null mutants, there were significant genotype by stress interactions for shelter exits $\left(F_{(1,37)}=6.08 ; p<0.05\right)$ and time out of the shelter $\left(F_{(1,37)}=14.12 ; p<0.01\right)$ during the first $5 \mathrm{~min}$. Post hoc comparisons showed that nonstressed $-/-$ mice exhibited a trend for more time out of the shelter than $+/+$ mice, consistent with data in other assays (Boyce-Rustay and Holmes, 2006). Stress produced a significant, C57BL/ 6J-like increase in shelter exits and time out of the shelter in $+/+$ mice, but had no effects on exits and significantly decreased time out of the shelter in $-/-$ mice, as compared to nonstressed $-/-$ mice (Fig. 5A,B). There was a trend for shorter latency to exit after stress, but no main effects or interaction (Fig. $5 C)$. There was a significant effect of stress $\left(F_{(1,29)}=64.83 ; p<0.01\right)$, but not genotype and no interaction, for body weight. Stress significantly reduced body weight regardless of genotype (Fig. $5 D$ ).

In GluR1 null mutants, there was a significant effect of stress but no stress-genotype interaction for time out of the shelter $\left(F_{(1,37)}=9.13 ; p<0.01\right)$ and shelter exits $\left(F_{(1,37)}=9.77 ; p<\right.$ $0.01)$. Stress significantly increased both measures regardless of genotype (Table 1$).-/-$ mice made significantly more shelter exits than $+/+$ mice (main genotype effect, $F_{(1,37)}=8.04 ; p<0.01$ ). Neither stress nor genotype affected latency to exit the shelter. There was a significant effect of stress $\left(F_{(1,37)}=18.12 ; p<0.01\right)$, but not 
genotype and no interaction, for body weight. Stress significantly reduced body weight regardless of genotype (Table 1).

NR2A null mutant amygdala neuronal dendritic morphology and spine density

There was a significant effect of genotype $\left(F_{(1,12)}=4.90 ; p<0.05\right)$ and branch order $\left(F_{(3,12)}=94.10 ; p<.05\right)$, but no interaction, for spine density. $-/-$ mice had a significantly $(\sim 30 \%)$ lower spine density than $+/+$ mice, regardless of branch order (Fig. 6A,B). Overall amount of dendritic material, dendritic branch number, and branch length, either in all branches or terminal branches only, were unaffected by genotype (Fig. 6C-F).

\section{Discussion}

The current data demonstrate significant variation in basal and stress-induced anxiety-related behavior in different inbred mouse strains. This variation correlated with divergent corticolimbic gene expression and excitatory glutamatergic signaling in the amygdala. Null mutation of the modulatory NMDAR NR2A subunit was sufficient to reverse stress-induced changes in behavior.

\section{Effects of strain and stress on anxiety- and depression-related behavior}

Our strain survey revealed that DBA/2J had higher basal anxietylike behavior than $\mathrm{C} 57 \mathrm{BL} / 6 \mathrm{~J}$ in two separate behavioral assays (light/dark exploration test and elevated plus maze), as found previously in some but not all studies (e.g., Bouwknecht and Paylor, 2002; Anisman and Matheson, 2005; Hovatta et al., 2005; DuBois et al., 2006; Mineur et al., 2006; Millstein and Holmes, 2007; Cohen et al., 2008; Schweizer et al., 2009). DBA/2J responded to repeated restraint stress with further increase in anxiety-like behavior (i.e., reduced exploration of aversive areas) in the light/dark exploration test, but not the elevated plus maze (possibly because of a baseline floor effect as corticosterone levels after plus-maze exposure were indeed demonstrably elevated in stressed, relative to nonstressed, DBA/2J). C57BL/6J responded to stress in the opposite manner (i.e., increased exploration of the open areas) in both tests. One explanation is that DBA/2J is "susceptible" to this stressor, whereas C57BL/6J is "resilient." However, a more circumscribed but potentially more accurate interpretation is that both strains react strongly to this particular stress regime, but differ in the manner in which the response manifests behaviorally. Thus, DBA/2J may develop a classic "passive" anxiety-like suppression of approach behavior, whereas C57BL/6J may exhibit more of an "active" response to stress. This could reflect an increased panic-like escape drive or manic-like reaction to stress in C57BL/6J, rather than a decrease in anxiety-like behavior. Indeed, previous studies have found that C57BL/6J (and DBA/2J) exhibit strong anxiety-like reactions to certain other stressors (e.g., acute predator odor exposure) (Cohen et al., 2008). The nature of the behavioral response to repeated restraint in both strains could be parsed further by testing its reversibility by drug classes with efficacy in normalizing different diseases states (e.g., anti-anxiety, anti-panic, anti-manic).
Table 1. Stress-induced anxiety-related behavior in GluR1 null mutants

\begin{tabular}{|c|c|c|c|c|}
\hline & \multicolumn{2}{|l|}{$+1+$} & \multicolumn{2}{|l|}{$-1-$} \\
\hline & Nonstressed & Stressed & Nonstressed & Stressed \\
\hline $\begin{array}{l}\% \text { of time out of } \\
\text { shelter }\end{array}$ & $20.75 \pm 4.89$ & $28.39 \pm 2.55$ & $20.07 \pm 1.98$ & $32.54 \pm 2.46$ \\
\hline Shelter exits**,\#\# & $11.27 \pm 2.42$ & $19.36 \pm 1.48$ & $18.67 \pm 1.83$ & $25.50 \pm 3.36$ \\
\hline Latency to first exit & $58.00 \pm 25.68$ & $24.14 \pm 6.40$ & $24.37 \pm 4.88$ & $15.50 \pm 5.17$ \\
\hline $\begin{array}{l}\text { Body weight change } \\
(\mathrm{g})^{* *}\end{array}$ & $1.07 \pm 0.32$ & $-1.76 \pm 0.71$ & $0.81 \pm 0.29$ & $-1.56 \pm 0.65$ \\
\hline
\end{tabular}

Repeated restraint stress produced a significant increase in time out of the shelter and shelter exits, and a significant decrease in body weight, compared to nonstress controls, regardless of genotype. Stress did not significantly affect latency to exit. $n=9-10$ per genotype under. Data are expressed as mean \pm SEM. ${ }^{*} p<0.05$; ${ }^{* *} p<0.01$, main effect of stress; ${ }^{\# \#} p<0.01$ main effect of genotype.

The differential response to stress in anxiety-related measures between C57BL/6J and DBA/2J did not generalize to measures of depression-related behavior. Repeated restraint produced an equivalent loss of body weight and sensitization of the corticosterone response to forced swim stress in DBA/2J and C57BL/6J, but had no effects on forced swim test depression-related behavior. Thus, anxiety-like behavior may be an especially sensitive readout of the effects of repeated restraint, as it is for other repeated stressors, in mice (Strekalova et al., 2004; Krishnan et al., 2007).

\section{Effects of strain and stress on corticolimbic gene expression}

There is mounting evidence that genetically driven variation in corticolimbic function underlies individual differences in anxiety and stress (Caspi et al., 2010). Genome-wide analyses have identified patterns of gene expression underlying strain (Hovatta et al., 2005) and strain-subpopulation (Krishnan et al., 2007) differences in trait and stress-induced alterations in anxiety. Gene expression in amygdala, vmPFC, and hippocampus differed markedly at baseline between DBA/2J and C57BL/6J, with an approximately equivalent number of differences in each region [similar to the regional uniformity reported by Kerns et al., 

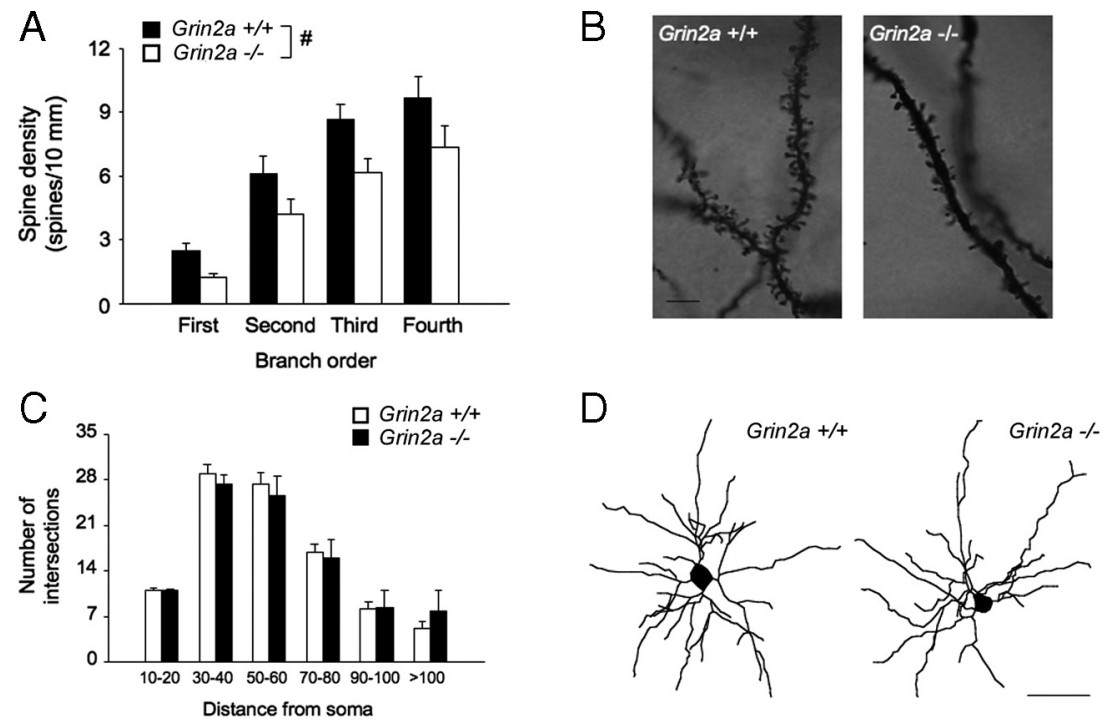

E

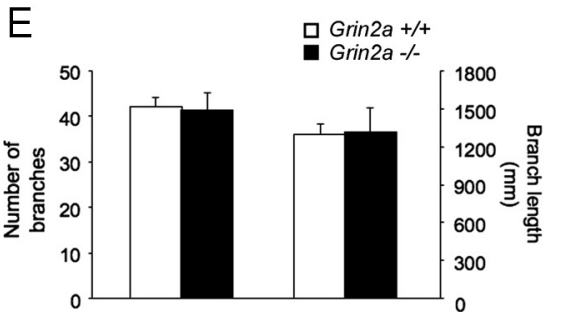

$\mathrm{F}$

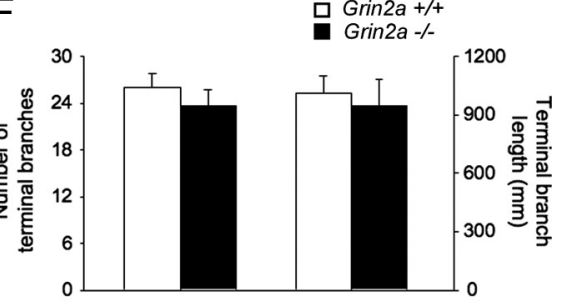

Figure 6. Amygdala dendritic morphology and neuronal spine density in NR2A null mutants. $A$, Nonstressed $-/-$ mice had significantly lesser spine density in principal BLA neurons than $+/+$ mice, regardless of branch order ( $n=6-8$ per genotype). $\boldsymbol{B}$, Representative images of Golgi-Cox stained dendritic spines. $\boldsymbol{C}$, The overall amount of dendritic material, as measured by the number of intersections by distance from soma, did not differ between genotypes. $\boldsymbol{D}$, Representative images of reconstructed neurons. $S$ cale bar, $50 \mu \mathrm{m}$. $\boldsymbol{E}$, Genotypes did not differ in branch number or branch length. $\boldsymbol{F}$, Genotypes did not differ in terminal branch number or branch length. $n=6-8$ per genotype. Data are expressed as mean \pm SEM. ${ }^{*} p<0.05,+1+$ versus $-1-$ mice.

(2005)]. Previous studies have also reported major differential basal gene expression between the strains in various forebrain regions, including the PFC and striatum (Hovatta et al., 2005; Kerns et al., 2005; Korostynski et al., 2006; Grice et al., 2007). Some of the genes our analysis found to differ between strains have been reported previously to differ in other regions. For example, the higher expression of Comt we found in the vmPFC of $\mathrm{C} 57 \mathrm{BL} / 6 \mathrm{~J}$ relative to $\mathrm{DBA} / 2 \mathrm{~J}$ has also been reported in the nucleus accumbens (Grice et al., 2007), and the differential expression and putative splice variation of Atp 1a2 between these two strains has also been detected in the striatum (Korostynski et al., 2006).

We confirmed expression differences driven by strain and/or or stress in 16 genes. Eight have previously been linked to anxietyand stress-related behaviors: Gal (galanin) (e.g., Karlsson and Holmes, 2006), Atp1a2 (sodium pump $\alpha 2$ subunit) (e.g., Ikeda et al., 2003), $B d n f$ (brain-derived nerve growth factor) (e.g., Nestler et al., 2002), Nr4a2 (Nurr1) (e.g., Rojas et al., 2007), Chrna4 ( $\alpha 4$ nicotinic receptor) (e.g., Labarca et al., 2001), Comt (catechol-Omethyltransferase) (e.g., Zubieta et al., 2003; Papaleo et al., 2008), Drd1a (dopamine D1 receptor) (e.g., Hains and Arnsten, 2008), and $R g s 2$ (Yalcin et al., 2004). Another four genes are key components of glutamate-mediated neurotransmission and neural plasticity (Malenka and Bear, 2004; Szumlinski et al., 2004, 2005): Grik1 (glutamate receptor, ionotropic, kainate 1), Grin1 (glutamate receptor, ionotropic, NMDA 1), Grial (glutamate receptor, ionotropic, AMPA 1), and Homer1 (Homer homolog 1). The final three genes we examined are circadian genes (the period homologs Per1, Per2, and their regulator Dbp, D-box binding pro- tein), increasingly implicated circadian genes in stress-related neuropsychiatric diseases such as mania (McClung, 2007).

At the systems level, of the three brain regions analyzed, stress produced the most expression changes in the amygdala in both strains. This is consistent with the amygdala being the central node within the corticolimbic "stress" network and its exquisite sensitivity to genetic factors and stress (LeDoux, 2000; Vyas et al., 2002; Hariri and Holmes, 2006; Yang et al., 2008). Critically however, stress affected an almost entirely different set of genes in $\mathrm{DBA} / 2 \mathrm{~J}$ than C57BL/6J (in the amygdala as well as vmPFC and hippocampus). For example, stress caused ubiquitous upregulation of circadian (e.g., period) genes in DBA/2J, but altered plasticity-related (e.g., glutamate receptor) genes in C57BL/ 6J. These data argue against a canonically common molecular "stress network" activated to different degrees in the two strains, but instead suggest the mobilization of mostly autonomous gene networks. They are also in line with the divergent behavioral responses to stress in $\mathrm{DBA} / 2 \mathrm{~J}$ and $\mathrm{C} 57 \mathrm{BL} / 6 \mathrm{~J}$ being qualitative, rather than simply quantitative, in nature.

\section{Stress effects on amygdala neuronal excitability and metaplasticity}

Our expression analysis nominates various gene sets as correlates of the divergent behavioral response to stress in $\mathrm{DBA} / 2 \mathrm{~J}$ and C57BL/6J. In the current study, we chose to focus further on the glutamate system because this system mediates both corticolimbic excitability and plasticity. Stress augmented temporal summation of NMDAR-mediated currents in BLA neurons in DBA/2J but not C57BL/6J. This effect was evident specifically at subsaturation stimulation frequencies and in the absence of altered NMDAR-mediated current duration. Temporal summation assays metaplasticity ("the plasticity of synaptic plasticity") (Philpot et al., 2001; Kash et al., 2009) and provides a surrogate measure of the excitatory neuronal response in the face of accumulating extracellular glutamate (Kullmann et al., 1996). Enhanced summation after stress in DBA/2J could reflect impaired regulation of glutamatergic neurotransmission at the presynaptic (reduced release by metabotropic glutamate or cannabinoid receptors), glial (reduced glutamate reuptake), or postsynaptic (increased spillover activation of perisynaptic/extrasynaptic NMDARs) levels.

Additional studies will be needed to elucidate these mechanisms. Notwithstanding, the main conclusion is that the heightened anxiety-related response to stress in DBA/2J is associated with increased amygdala neuronal excitability. A similar association has been reported in other models, such as in rodents selectively bred for high-anxiety-like behavior (Muigg et al., 2007). It was notable that these physiological changes occurred in this strain, whereas changes in amygdala expression of plasticity genes, including glutamate receptors, were evident in C57BL/6J. We hypothesize that these expression changes reflect the orchestration of neuroadaptations that serve to effectively "protect" 
against amygdala hyperexcitability in $\mathrm{C} 57 \mathrm{BL} / 6 \mathrm{~J}$. The failure to recruit these mechanisms in $\mathrm{DBA} / 2 \mathrm{~J}$ could underlie the increased passive-like anxiety-like response to stress. This could potentially have implications for developing novel drug treatments for stress-related anxiety disorders that target the glutamate system to mitigate the development or expression of adverse reactions to stress.

\section{Stress effects in NR2A and GluR1 null mutants}

Divergent mobilization of the glutamate system per se is unlikely to fully account for the differential strain responses to stress. However, supporting the importance of these particular changes, null mutation (on a C57BL/6J background) of one key modulatory component, the NMDAR NR2A subunit, was not only sufficient to prevent the $\mathrm{C} 57 \mathrm{BL} / 6 \mathrm{~J}$-like anxiety-related response to stress, but partially reversed the direction of these effects, i.e., producing a DBA/2J-like increase in anxiety-like behavior. Demonstrating the specificity of the contribution of NR2A, null mutation of another key glutamate receptor, AMPA GluR1 (also on a C57BL/6J background), did not mitigate the C57BL/6J-like response to stress. In addition, BLA dendritic spine density was significantly reduced in NR2A null mutants under basal conditions. This is noteworthy because increased BLA dendritic spine density (and length) is posited to be a neuronal correlate of stressinduced increases in anxiety-like behavior (in rats) (Vyas et al., 2006). Thus, current data raise the intriguing possibility that basal status of BLA spine density may determine the nature of the anxiety-related response (i.e., C57BL/6J-like or DBA/2J-like) to stress.

\section{Summary and conclusions}

In summary, our initial strain survey identified two strains exhibiting divergent basal and stress-induced anxiety-related phenotypes, DBA/2J and C57BL/6J. This behavioral variation was associated with marked differences in the expression of corticolimbic genes expressed at baseline and in response to stress. Differential recruitment of glutamate plasticity genes characterized strain differences in gene expression. Metaplasticity of NMDAR-mediated neuronal amygdala signaling was impaired in the strain (DBA/2J) showing a passive anxiety-related response to stress, but not the strain (C57BL/6J) exhibiting an active behavioral response to stress and effective mobilization of plasticity genes in the amygdala. Finally, null mutation of NR2A (but not GluR1) was sufficient to prevent and partially reverse the active, C57BL/6J-like anxiety-related response to stress, and caused a decrease of BLA dendritic spines. Our findings could have implications for elucidating the neural and genetic basis of individual differences in risk for stress-related neuropsychiatric disease.

\section{References}

Anisman H, Matheson K (2005) Stress, depression, and anhedonia: caveats concerning animal models. Neurosci Biobehav Rev 29:525-546.

Belzung C, Griebel G (2001) Measuring normal and pathological anxietylike behaviour in mice: a review. Behav Brain Res 125:141-149.

Berton O, Nestler EJ (2006) New approaches to antidepressant drug discovery: beyond monoamines. Nat Rev Neurosci 7:137-151.

Bouwknecht JA, Paylor R (2002) Behavioral and physiological mouse assays for anxiety: a survey in nine mouse strains. Behav Brain Res 136:489-501.

Boyce-Rustay JM, Holmes A (2006) Genetic inactivation of the NMDA receptor NR2A subunit has anxiolytic- and antidepressant-like effects in mice. Neuropsychopharmacology 31:2405-2414.

Boyce-Rustay JM, Cameron HA, Holmes A (2007) Chronic swim stress alters sensitivity to acute behavioral effects of ethanol in mice. Physiol Behav 91:77-86.

Brigman JL, Feyder M, Saksida LM, Bussey TJ, Mishina M, Holmes A (2008)
Impaired discrimination learning in mice lacking the NMDA receptor NR2A subunit. Learn Mem 15:50-54.

Brigman JL, Mathur P, Lu L, Williams RW, Holmes A (2009) Genetic relationship between anxiety- and fear-related behaviors in BXD recombinant inbred mice. Behav Pharmacol 20:204-209.

Caspi A, Hariri AR, Holmes A, Uher R, Moffitt TE (2010) Genetic sensitivity to the environment: the case of the serotonin transporter gene and its implications for studying complex diseases and traits. Am J Psychiatry. Advance online publication. Retrieved March 28, 2010. PMID: 20231323.

Cohen H, Geva AB, Matar MA, Zohar J, Kaplan Z (2008) Post-traumatic stress behavioural responses in inbred mouse strains: can genetic predisposition explain phenotypic vulnerability? Int J Neuropsychopharmacol 11:331-349.

Crawley JN (1981) Neuropharmacologic specificity of a simple animal model for the behavioral actions of benzodiazepines. Pharmacol Biochem Behav 15:695-699.

Cryan CF, Dev KK (2007) The glutamatergic system as a potential therapeutic target for the treatment of anxiety disorders. In: Handbook of anxiety and fear (Blanchard RJ, Blanchard DC, Nutt DJ, eds), pp 279-302, Amsterdam: Elsevier.

Cryan JF, Holmes A (2005) The ascent of mouse: advances in modelling human depression and anxiety. Nat Rev Drug Discov 4:775-790.

DuBois DW, Perlegas A, Floyd DW, Weiner JL, McCool BA (2006) Distinct functional characteristics of the lateral/basolateral amygdala GABAergic system in C57BL/6J and DBA/2J mice. J Pharmacol Exp Ther 318:629-640.

Glaser EM, Van der Loos H (1981) Analysis of thick brain sections by obverse-reverse computer microscopy: application of a new, high-quality Golgi-Nissl stain. J Neurosci Methods 4:117-125.

Grice DE, Reenila I, Mannisto PT, Brooks AI, Smith GG, Golden GT, Buxbaum JD, Berrettini WH (2007) Transcriptional profiling of C57 and DBA strains of mice in the absence and presence of morphine. BMC Genomics 8:76.

Hains AB, Arnsten AF (2008) Molecular mechanisms of stress-induced prefrontal cortical impairment: implications for mental illness. Learn Mem 15:551-564.

Hariri AR, Holmes A (2006) Genetics of emotional regulation: the role of the serotonin transporter in neural function. Trends Cogn Sci 10:182-191.

Hefner K, Holmes A (2007) An investigation of the behavioral actions of ethanol across adolescence in mice. Psychopharmacology (Berl) 191:311-322.

Holmes A, Rodgers RJ (2003) Prior exposure to the elevated plus-maze sensitizes mice to the acute behavioral effects of fluoxetine and phenelzine. Eur J Pharmacol 459:221-230.

Holmes A, Wellman CL (2009) Stress-induced prefrontal reorganization and executive dysfunction in rodents. Neurosci Biobehav Rev 33:773-783.

Hovatta I, Tennant RS, Helton R, Marr RA, Singer O, Redwine JM, Ellison JA, Schadt EE, Verma IM, Lockhart DJ, Barlow C (2005) Glyoxalase 1 and glutathione reductase 1 regulate anxiety in mice. Nature 438:662-666.

Ikeda K, Onaka T, Yamakado M, Nakai J, Ishikawa TO, Taketo MM, Kawakami K (2003) Degeneration of the amygdala/piriform cortex and enhanced fear/anxiety behaviors in sodium pump $\alpha 2$ subunit (Atp1a2)deficient mice. J Neurosci 23:4667-4676.

Jacobson LH, Cryan JF (2007) Feeling strained? Influence of genetic background on depression-related behavior in mice: a review. Behav Genet 37:171-213.

Karlsson RM, Holmes A (2006) Galanin as a modulator of anxiety and depression and a therapeutic target for affective disease. Amino Acids 31:231-239.

Kash TL, Baucum AJ, 2nd, Conrad KL, Colbran RJ, Winder DG (2009) Alcohol exposure alters NMDAR function in the bed nucleus of the stria terminalis. Neuropsychopharmacology 34:2420-2429.

Kerns RT, Ravindranathan A, Hassan S, Cage MP, York T, Sikela JM, Williams RW, Miles MF (2005) Ethanol-responsive brain region expression networks: implications for behavioral responses to acute ethanol in DBA/2J versus C57BL/6J mice. J Neurosci 25:2255-2266.

Korostynski M, Kaminska-Chowaniec D, Piechota M, Przewlocki R (2006) Gene expression profiling in the striatum of inbred mouse strains with distinct opioid-related phenotypes. BMC Genomics 7:146.

Krishnan V, Han MH, Graham DL, Berton O, Renthal W, Russo SJ, Laplant 
Q, Graham A, Lutter M, Lagace DC, Ghose S, Reister R, Tannous P, Green TA, Neve RL, Chakravarty S, Kumar A, Eisch AJ, Self DW, Lee FS, et al. (2007) Molecular adaptations underlying susceptibility and resistance to social defeat in brain reward regions. Cell 131:391-404.

Kullmann DM, Erdemli G, Asztely F (1996) LTP of AMPA and NMDA receptor-mediated signals: evidence for presynaptic expression and extrasynaptic glutamate spill-over. Neuron 17:461-474.

Labarca C, Schwarz J, Deshpande P, Schwarz S, Nowak MW, Fonck C, Nashmi R, Kofuji P, Dang H, Shi W, Fidan M, Khakh BS, Chen Z, Bowers BJ, Boulter J, Wehner JM, Lester HA (2001) Point mutant mice with hypersensitive alpha 4 nicotinic receptors show dopaminergic deficits and increased anxiety. Proc Natl Acad Sci U S A 98:2786-2791.

Larkman AU (1991) Dendritic morphology of pyramidal neurones of the visual cortex of the rat: I. Branching patterns. J Comp Neurol 306:307-319.

LeDoux JE (2000) Emotion circuits in the brain. Annu Rev Neurosci 23: $155-184$.

Livak KJ, Schmittgen TD (2001) Analysis of relative gene expression data using real-time quantitative PCR and the 2(-Delta Delta C(T)) method. Methods 25:402-408.

Malenka RC, Bear MF (2004) LTP and LTD: an embarrassment of riches. Neuron 44:5-21.

McClung CA (2007) Circadian genes, rhythms and the biology of mood disorders. Pharmacol Ther 114:222-232.

Millstein RA, Holmes A (2007) Effects of repeated maternal separation on anxiety- and depression-related phenotypes in different mouse strains. Neurosci Biobehav Rev 31:3-17.

Millstein RA, Ralph RJ, Yang RJ, Holmes A (2006) Effects of repeated maternal separation on prepulse inhibition of startle across inbred mouse strains. Genes Brain Behav 5:346-354.

Milner LC, Crabbe JC (2008) Three murine anxiety models: results from multiple inbred strain comparisons. Genes Brain Behav 7:496-505.

Mineur YS, Belzung C, Crusio WE (2006) Effects of unpredictable chronic mild stress on anxiety and depression-like behavior in mice. Behav Brain Res 175:43-50.

Muigg P, Hoelzl U, Palfrader K, Neumann I, Wigger A, Landgraf R, Singewald N (2007) Altered brain activation pattern associated with drug-induced attenuation of enhanced depression-like behavior in rats bred for high anxiety. Biol Psychiatry 61:782-796.

Nestler EJ, Barrot M, DiLeone RJ, Eisch AJ, Gold SJ, Monteggia LM (2002) Neurobiology of depression. Neuron 34:13-25.

Norcross M, Mathur P, Enoch AJ, Karlsson RM, Brigman J, Cameron HA, Harvey-White J, Holmes A (2008) Fluoxetine treatment during adolescence does not cause lasting deficits in fear-, anxiety- or stress-related behaviors in mice. Psychopharmacology (Berl) 200:413-424.

Papaleo F, Crawley JN, Song J, Lipska BK, Pickel J, Weinberger DR, Chen J (2008) Genetic dissection of the role of catechol-O-methyltransferase in cognition and stress reactivity in mice. J Neurosci 28:8709-8723.

Peters A, Kaiserman-Abramof IR (1970) The small pyramidal neuron of the rat cerebral cortex. The perikaryon, dendrites and spines. Am J Anat 127: 321-355.

Philpot BD, Sekhar AK, Shouval HZ, Bear MF (2001) Visual experience and deprivation bidirectionally modify the composition and function of NMDA receptors in visual cortex. Neuron 29:157-169.

Ponder CA, Kliethermes CL, Drew MR, Muller J, Das K, Risbrough VB, Crabbe JC, Gilliam TC, Palmer AA (2007) Selection for contextual fear conditioning affects anxiety-like behaviors and gene expression. Genes Brain Behav 6:736-749.

Porsolt RD, Le Pichon M, Jalfre M (1977) Depression: a new animal model sensitive to antidepressant treatments. Nature 266:730-732.

Pothion S, Bizot JC, Trovero F, Belzung C (2004) Strain differences in sucrose preference and in the consequences of unpredictable chronic mild stress. Behav Brain Res 155:135-146.

Rojas P, Joodmardi E, Hong Y, Perlmann T, Ogren SO (2007) Adult mice with reduced Nurr1 expression: an animal model for schizophrenia. Mol Psychiatry 12:756-766.

Roozendaal B, McEwen BS, Chattarji S (2009) Stress, memory and the amygdala. Nat Rev Neurosci 10:423-433.

Sakimura K, Kutsuwada T, Ito I, Manabe T, Takayama C, Kushiya E, Yagi T, Aizawa S, Inoue Y, Sugiyama H, Mishina M (1995) Reduced hippocampal LTP and spatial learning in mice lacking NMDA receptor epsilon 1 subunit. Nature 373:151-155.

Schweizer MC, Henniger MS, Sillaber I (2009) Chronic mild stress (CMS) in mice: of anhedonia, "anomalous anxiolysis" and activity. PLoS One 4:e4326.

Shansky RM, Hamo C, Hof PR, McEwen BS, Morrison JH (2009) Stressinduced dendritic remodeling in the prefrontal cortex is circuit specific. Cereb Cortex 19:2479-2484.

Strekalova T, Spanagel R, Bartsch D, Henn FA, Gass P (2004) Stressinduced anhedonia in mice is associated with deficits in forced swimming and exploration. Neuropsychopharmacology 29:2007-2017.

Szumlinski KK, Dehoff MH, Kang SH, Frys KA, Lominac KD, Klugmann M, Rohrer J, Griffin W 3rd, Toda S, Champtiaux NP, Berry T, Tu JC, Shealy SE, During MJ, Middaugh LD, Worley PF, Kalivas PW (2004) Homer proteins regulate sensitivity to cocaine. Neuron 43:401-413.

Szumlinski KK, Lominac KD, Kleschen MJ, Oleson EB, Dehoff MH, Schwarz MK, Seeburg PH, Worley PF, Kalivas PW (2005) Behavioral and neurochemical phenotyping of Homerl mutant mice: possible relevance to schizophrenia. Genes Brain Behav 4:273-288.

Turri MG, Datta SR, DeFries J, Henderson ND, Flint J (2001) QTL analysis identifies multiple behavioral dimensions in ethological tests of anxiety in laboratory mice. Curr Biol 11:725-734.

Vyas A, Mitra R, Shankaranarayana Rao BS, Chattarji S (2002) Chronic stress induces contrasting patterns of dendritic remodeling in hippocampal and amygdaloid neurons. J Neurosci 22:6810-6818.

Vyas A, Jadhav S, Chattarji S (2006) Prolonged behavioral stress enhances synaptic connectivity in the basolateral amygdala. Neuroscience 143:387-393.

Wellman CL, Izquierdo A, Garrett JE, Martin KP, Carroll J, Millstein R, Lesch KP, Murphy DL, Holmes A (2007) Impaired stress-coping and fear extinction and abnormal corticolimbic morphology in serotonin transporter knock-out mice. J Neurosci 27:684-691.

Wiedholz LM, Owens WA, Horton RE, Feyder M, Karlsson RM, Hefner K, Sprengel R, Celikel T, Daws LC, Holmes A (2008) Mice lacking the AMPA GluR1 receptor exhibit striatal hyperdopaminergia and "schizophreniarelated" behaviors. Mol Psychiatry 13:631-640.

Willner P, Moreau JL, Nielsen CK, Papp M, Sluzewska A (1996) Decreased hedonic responsiveness following chronic mild stress is not secondary to loss of body weight. Physiol Behav 60:129-134.

Yalcin B, Willis-Owen SA, Fullerton J, Meesaq A, Deacon RM, Rawlins JN, Copley RR, Morris AP, Flint J, Mott R (2004) Genetic dissection of a behavioral quantitative trait locus shows that Rgs 2 modulates anxiety in mice. Nat Genet 36:1197-1202.

Yang RJ, Mozhui K, Karlsson RM, Cameron HA, Williams RW, Holmes A (2008) Variation in mouse basolateral amygdala volume is associated with differences in stress reactivity and fear learning. Neuropsychopharmacology 33:2595-2604.

Yehuda R, LeDoux J (2007) Response variation following trauma: a translational neuroscience approach to understanding PTSD. Neuron 56:19-32.

Zamanillo D, Sprengel R, Hvalby O, Jensen V, Burnashev N, Rozov A, Kaiser KM, Koster HJ, Borchardt T, Worley P, Lubke J, Frotscher M, Kelly PH, Sommer B, Andersen P, Seeburg PH, Sakmann B (1999) Importance of AMPA receptors for hippocampal synaptic plasticity but not for spatial learning. Science 284:1805-1811.

Zubieta JK, Heitzeg MM, Smith YR, Bueller JA, Xu K, Xu Y, Koeppe RA, Stohler CS, Goldman D (2003) COMT val158met genotype affects muopioid neurotransmitter responses to a pain stressor. Science 299:12401243. 